\title{
Aprendizagem e desenvolvimento de competências: articulando teoria e prática em programas de pós- graduação em formação gerencial
}

\author{
Roberto Ruas* \\ Graziella Maria Comini**
}

\begin{abstract}
Resumo
Uma análise desenvolvida em programas de pós-graduação em formação gerencial revela que o currículo e os métodos pedagógicos empregados nesses cursos não estão adequadamente relacionados com as condições do ambiente de trabalho profissional dos alunos, condições nas quais as competências gerenciais poderiam ser mobilizadas e desenvolvidas.

Sustentado em surveys e entrevistas com cerca de 300 alunos participantes de 14 cursos de pós-graduação em formação gerencial, este artigo recupera contribuições associadas a diferentes abordagens da aprendizagem, tais como sistemas de aprendizagem social, aprendizagem pela experiência, aprendizagem experiencial, aprendizagem situada e comunidades de aprendizagem. 0 objetivo é construir referências para o desenvolvimento de competências em ambiente de programas de pós-graduação em formação gerencial.
\end{abstract}

Palavras-chave: formação gerencial; desenvolvimento de competências; abordagens de aprendizagem.

\begin{abstract}
An analysis carried out in Brazilian programs of executive education reveals that the curricula and the pedagogic methods of these courses are not completely linked with particularities of the work environment, so they are apart of the conditions in which the competences will be developed. Based on surveys and interviews applied to around 300 students participating in 14 programs of managerial formation, this articles points out the contribution of some learning approaches: social learning systems, experiential learning, situated leaning and learning communities. The objective of this proposal is to build some references for competence development in programs of executive education.
\end{abstract}

Key words: executive education; competencies development; learning approaches.

\section{Introdução}

No Brasil, o impacto dos programas de pós-graduação em formação gerencial (mestrados profissionais, MBAs e especialização em gestão) nas competências e no desempenho profissional dos seus alunos não tem sido um tema freqüente no debate e na pesquisa em administração. Paradoxalmente, nos últimos anos, a oferta desse tipo de programa tem crescido no país de forma vertiginosa, aproximadamente, 136\% entre 1987 e 2004 (VOCÊ S/A, 2006). Parte desses programas tem obtido reconhecimento e valorização no ambiente econômico, empresarial e acadêmico, em função de sua tradição, dos professores que ali atuam, dos profissionais que os procuram como alunos ou, ainda, em razão das empresas que deles participam.

\footnotetext{
Doutor em Economia - Universidade Amiens - França. Professor da Escola de Administração da Universidade Federal do Rio Grande do Sul. Endereço: $\mathbf{R}$. Washington Luiz, 855 - 90040-000 - Porto Alegre RS. E-mail: rlruas@ ea.ufrgs.br.

*" Doutorado em Administração - FEA- USP. Endereço: FEA/USP - Av. Prof. Luciano Gualberto, 908, Sala E 120 - CEP 05508-900 - São Paulo-SP - E-mail: graziella@ growthconsultoria.com.br.

** Artigo recebido em novembro de 2006 e aceito para publicação em dezembro de 2006.
} 
Entretanto, a falta de um debate mais freqüente sobre essas questões gera uma lacuna, deixando a seguinte dúvida: de que maneira os programas de pós graduação em formação gerencial têm contribuído para melhor o desempenho profissional de seus egressos?

O pouco que se sabe a respeito resulta de observações empíricas especialmente de programas considerados de maior qualidade. O ponto forte desses programas está, sobretudo, no desenvolvimento cognitivo dos alunos, a partir do emprego de recursos didáticos calcados predominantemente no conhecimento. Trata-se de um processo no qual o aluno é estimulado a se apropriar de um conjunto de princípios, conceitos e métodos de gestão, distribuídos por disciplinas e seminários, cujos principais títulos e conteúdos são similares, se compararmos diferentes programas.

Segundo pesquisa apresentada mais adiante, grande parte dos alunos desses programas parecem estar conscientes de que, ao final dos cursos, tiveram a oportunidade de aprender quanto de rever importantes princípios e métodos da administração contemporânea. Da mesma forma, acreditam terem desenvolvido a capacidade de "ver e analisar o mundo", de entender a gestão contemporânea nas suas diferentes perspectivas, além de relacionar sua área de atuação com outras áreas da empresa e de fora dela.

Por outro lado, também é freqüente a percepção de que esses cursos, de forma geral, não atendem às expectativas dos alunos quanto ao desenvolvimento de competências. Nesse sentido, uma parte da literatura tem defendido a tese de que programas de formação gerencial convencionais tendem a gerar um gap entre o potencial de recursos desenvolvidos nesses programas (conhecimentos e algumas habilidades) e aquilo que é necessário e precisa ser apropriado como competência na atividade profissional. (Mintzberg, 2006).

Buscando justificativas para esse gap, um diagnóstico muito replicado no ambiente empresarial é o de que esses processos de formação são desenvolvidos de maneira relativamente distante das condições e especificidades do trabalho; ou seja, distante das condições onde as competências serão desenvolvidas.

Também no contexto acadêmico têm sido produzidos trabalhos que direta ou indiretamente tratam de forma crítica desses programas: de sua pouca consistência, da "quase" padronização de seus currículos e disciplinas, do emprego de metodologias pedagógicas convencionais e da ênfase em "gurus". (FISCHER, 2001; RUAS, 2003; SOUZA; SOUZA; ASSIS; ZERBINI, 2004; WOOD JUNIOR; PAES DE PAULA, 2004, FESTINALLI, 2005). Numa perspectiva ainda crítica, alguns trabalhos apontam alternativas para o ensino-aprendizagem em administração: abordagens que reforçam a necessidade da relação teoria e prática (STAHL,2004; NASSIF; GHOBRIL;BIDO, 2005), ou que destacam a importância da noção de competências como referência na construção de programas pedagógicos em administração (ANTONELLO; DUTRA, 2005; NUNES; FERRAZ, 2005) ou ainda, que centram a iniciativa da mudança no próprio docente (ANDRADE; MAHEU;OLIVEIRA, 2004); abordagens exploratórias, propondo o emprego de recursos alternativos no processo de ensinoaprendizagem, tais como elementos próprios à linguagens artística - cinema, teatro, dança, fotografia, música- a fim de desenvolver uma concepção estética de aprendizagem ( DAVEL; VERGARA, 2004), especificamente o uso da literatura (FISCHER; DAVEL; VERGARA; GHADIRI, 2006) ou das artes cênicas ( RUAS; WOOD JR., 2006)

Por outro lado, a direção dos PPFGs não tem contribuído neste esforço de compreensão e análise da questão da efetividade dos programas de formação gerencial. Salvo raras exceções, adotam procedimentos convencionais, como avaliar a assimilação de conteúdos - através de provas e trabalhos de conclusão, por exemplo -, avaliar a reação dos alunos diante de uma disciplina ou seminário, o que eles acham do desempenho do professor etc. Em geral, tais programas tratam seus processos como se estes fossem de desenvolvimento estritamente cognitivo e não de formação profissional..

Visando contribuir com este debate, este artigo analisa e avalia as percepções quanto à aprendizagem em programas de pós-graduação em formação gerencial (PPFGs) levantadas no período entre 2003 e 2006, junto a cerca de 300 alunos distribuídos por 14 turmas, compreendendo quatro mestrados profissionais, três MBAs e 
sete especializações lato sensu, ${ }^{1}$ cursos esses realizados em quatro diferentes instituições de ensino. Nessa avaliação, os alunos procuram identificar, sistematizar e priorizar o que perceberam como aprendizagem mais significativa durante o curso, considerando as competências que julgam importante desenvolver em sua atividade profissional.

Dentre os resultados mais significativos dessa pesquisa, destaque para a comparação entre as expectativas dos alunos, levantadas no início de alguns desses cursos, e a auto-avaliação de aprendizagem, realizada no seu final. Essa comparação revela diferenças importantes entre expectativas e o que é efetivamente desenvolvido num programa desse tipo, ainda segundo a expectativa dos alunos.

Os resultados também revelam que estes não só percebem como valorizam seu próprio desenvolvimento no campo cognitivo-intelectual (organização de textos, análise e crítica, síntese, associação de idéias e situações em diferentes documentos), pois trata-se de capacidades muito menos exploradas no ambiente organizacional. Essa percepção positiva, contudo, não impede que apontem também a necessidade de experimentação de métodos e conceitos em seus ambientes de trabalho. De acordo com os alunos, essa prática poderia aproximar mais os conteúdos de aula com as expectativas quanto ao desenvolvimento de competências; em outras palavras, articular o aprendizado cognitivo com o ambiente de trabalho, aspecto que será ainda retomado neste artigo.

\section{0 contexto e a emergência dos programas de formação gerencial}

Dentre os elementos mais visíveis no atual ambiente de negócios, destacam-se a velocidade, a tecnologia, a expansão internacional, a concentração de capitais via aquisições, as alianças e fusões e, especialmente, a instabilidade e a baixa previsibilidade. Nesse ambiente, as organizações não sobrevivem se continuarem a atuar como faziam há poucos anos. Referindo-se a essa instabilidade, Zarifian (2001) chama a atenção para uma das dimensões do conceito de "evento", na qual novas demandas são continuamente incorporadas pelo ambiente através de novos usos potenciais de produtos, novas expectativas da clientela, novos entrantes, novas tecnologias; enfim, situações que exigem das empresas uma forte mobilização para que possam crescer ou, pelo menos, permanecer no mercado.

Esse contexto altamente competitivo e instável acaba tendo um forte impacto no papel e nas funções do gestor. De fato, algumas das chamadas funções gerenciais (como a análise de cenários, de situações e de problemas, o relacionamento e a negociação com clientes e colaboradores, além dos processos de tomada de decisão) tornam-se, nesse contexto, mais complexas e difíceis, tanto pela intensidade da concorrência quanto pela instabilidade do ambiente. Resulta daí uma grande expectativa em termos do desempenho dos gestores, de suas respostas "rápidas e confiáveis", a chamada "pressão por resultados".

É nesse quadro de expectativa generalizada em torno da performance dos gestores que aumenta significativamente a oferta de programas de pós-graduação voltados para a formação gerencial de longa duração, tais como mestrados profissionais e especialização em gestão lato sensu (doravante denominados genericamente de PFG - Programas de Pós-Gradução em Formação Gerencial) em quase todos os países. No Brasil, esse tipo de programa vem apresentando uma notável expansão a partir de meados dos anos 90.

Entre 1987 e 2004, a pós-graduação cresceu 136\% no país, saltando de 815 cursos para 1.925 (VOCÊ S/A, 2006). De um lado, essa demanda é estimulada pelos próprios profissionais, que vêem nesses cursos uma alternativa para enfrentarem os desafios e as expectativas em relação a sua performance - sobretudo, uma oportunidade de se diferenciarem nas suas carreiras -; de outro, as empresas têm a expectativa de que essa alternativa garanta melhores resultados a seus processos e negócios, com base na capacitação de seus profissionais.

No Brasil, os programas denominados MBAs são também, formalmente, programas de especialização lato sensu. Neste artigo, são empregadas as denominações que as instituições adotam para seus cursos. 


\section{Os programas de pós- graduação em formação gerencial (PPFGs) - mestrados profissionais, MBAs e especialização em gestão : avanços e limites}

O primeiro programa denominado Master of Business Administration (MBA) foi criado em 1908, na Universidade de Harvard. Em 1928, surgiu o segundo desses programas, na Universidade de Stanford.

A história dos programas MBAs nos EUA é marcada por periódicas inovações que, geradas numa ou noutra instituição, acabam se disseminando por quase todas as escolas: o advento do método "estudo de casos" (Harvard, anos 1920), a valorização da pesquisa acadêmica (Carnegie Institute of Technology, anos 1950), a divisão da gestão em funções (várias escolas, anos 1970) e o foco em estratégia (Harvard, anos 1980). (MINTZBERG, 2006). A partir dos anos 1990, os principais MBAs americanos e alguns europeus iniciaram um processo de internacionalização, instalando unidades de ensino em outros países ou organizando programas de formação distribuídos por diferentes países na forma de consórcio de quatro ou cinco instituições, por exemplo.

Latham, Latham e Whyte (2004) analisam a evolução dos MBAs, demarcando pelo menos dois movimentos principais. O primeiro, na década de 1960, quando ocorreu a profissionalização dos cursos a partir da contratação de acadêmicos tanto da área humana quanto da de exatas. Apesar do aumento vertiginoso m número de trabalhos e de pesquisas verificado a partir daquele momento, os autores enfatizam que boa parte dessa produção estava descolada da realidade e das necessidades práticas das organizações que contratavam os egressos. Além disso, esse movimento provocou a estruturação de conteúdos de forma extremamente departamentalizada, naquilo que os autores chamam de "especialização funcional". Ainda segundo Latham, Latham e Whyte, o principal impacto na formação dos alunos foi a falta de uma visão mais integrada da administração e desenvolvimento da capacidade racional, prevalecendo um entendimento um tanto linear. "Os alunos conseguem perceber apenas que números são números e pessoas são pessoas...”. (Ibid., p.7).

Quanto ao segundo movimento dos MBAs, Latham, Latham e Whyte observam que ele é marcado pelo desafio de desenvolver nos alunos a competência do pensamento sistêmico e a visão integrada que lhes possibilitem enfrentar as situações organizacionais. Para isso, os autores consideram fundamental não apen as redesenhar conteúdos, mas também adotar metodologias de ensino inovadoras.

Mintzberg (2006) é crítico e cético em relação à efetivação das mudanças necessárias aos programas de MBAs, particularmente, porque estas dependem fundamentalmente da vontade e da visão dos docentes, os quais estão presos a um paradigma ultrapassado que não tem como eixo central uma abordagem reflexiva para educação gerencial.

Algumas idéias inovadoras associadas a programas de desenvolvimento gerencial têm sido divulgadas na literatura internacional. Mazen, Jones e Sergenian anos 90 (2000) discutem formas de transformar uma classe numa learning organization, enquanto Isabella (2005) apresenta um projeto de ensino para uma disciplina voltada para o trabalho em equipe, no qual o aprendizado ocorre por meio de ações concretas. Por sua vez, Agut e Grau (2002) destacam a associação entre a aprendizagem no campo cognitivo e a experiência profissional. Já Conger e Xin (2000) entendem que os métodos pedagógicos mais adequados para a formação de um executivo atuando em ambiente instável e hipercompetitivo incluem aprendizagem na ação e experiências diversificadas em situações específicas. Raelin e Coghlan (2006) renovam e reafirmam suas proposições acerca da importância decisiva da relação com o trabalho e com o ambiente organizacional nos processos de aprendizagem e formação gerencial.

Deve ser observado que essas proposições tem relação direta ou indireta com o debate sobre as formas sociais de aprendizagem, abordagem na qual as interações entre, de um lado, indivíduos e ambientes e, de outro, teoria e prática, constituem suas principais fontes inspiradoras. (GHERARDI ; NICOLINI , 2003; WENGER , 2003).

No Brasil, os PPFGs são programas mais recentes, pois os primeiros cursos iniciam suas trajetórias no final da década de 1970. Inicialmente, adotaram o título de curso de Especialização em Administração, com uma carga horária em torno de 360 horas (às vezes, um pouco mais). Ao contrário dos programas americanos, em geral, 
reconhecidos como cursos stricto sensu (equivalentes a mestrado), no Brasil, os cursos de especialização equivalem a cursos lato sensu, ou seja, a mesma equivalência de especialização. Apenas na segunda metade dos anos 1990 apareceram os cursos de mestrado profissional; esses, sim, classificados como stricto sensu. (RUAS, 2003) ).

A partir de meados dos anos 90, em resposta a críticas à predominância de uma visão acadêmica e teórica nesses programas, alguns deles incluíram inovações pedagógicas mais orientadas para a prática, como jogos de empresas, simulações de laboratórios, estudos de casos, visitas técnicas à empresas e outros recursos, visando aproximar os cursos da problemática empresarial. Também procuram atrair empresas por meio da oferta de cursos direcionados à especificidade de seus negócios (cursos in company). Dessa perspectiva - e buscando uma diferenciação diante da grande oferta de especializações lato sensu no Brasil -, já no final dos anos 1990, algumas instituições passaram a chamar de MBAs os seus cursos de especialização, ainda que estes formalmente mantenham o status de cursos de pós-graduação lato sensu.

Em 1996, foi regulamentado o curso de mestrado profissional, por iniciativa da Coordenação de Aperfeiçoamento de Pessoal de Nível Superior (Capes), órgão vinculado ao Ministério da Educação e responsável pela regulação de cursos de pós-graduação. O diploma de mestre profissional equivale ao de pósgraduação stricto sensu, ou seja, ao mestrado tradicional. Por uma série de razões institucionais e por suas características específicas, os programas de mestrado profissional ainda não estão tão difundidos quanto outros cursos do gênero.

Apesar da quantidade e da diversidade de oferta de PPFGs em praticamente todo o mundo, alguns problemas e desafios têm sido apontados por vários observadores (DEHLER, 2006; MINTZBERG, 2006; MINTZBERG; GOSLING, 2003; PFEFFER E FONG, 2003). Um dos principais desafios, com certeza, é a questão pela qual iniciamos este artigo: os programas de pós-graduação em formação gerencial têm de fato viabilizado um melhor desempenho profissional a seus alunos-egressos?

Uma das formas que encontramos para tratar dessa questão foi desenvolver uma pesquisa com um número significativo de alunos desses programas. O objetivo era tentar saber como percebem a relação entre a aprendizagem e o desenvolvimento de competências no decorrer dos programas, considerando a perspectiva de suas atividades profissionais e ambiente de trabalho. Acreditamos que um dos resultados positivos desse esforço é ampliar a visibilidade entre usuários-alunos e empresas acerca das apropriações efetivas (competências/desempenhos ) que esse tipo de curso é capaz de mobilizar; .ou seja, levantar e analisar de forma sistemática o que os alunos percebem como aprendizagem, respaldados também na perspectiva da empresa onde atuam. Os principais resultados dessa pesquisa são apresentados a seguir.

\section{A avaliação da aprendizagem de conteúdos e experiências nos PPFGs: principais resultados}

A atividade aqui descrita foi iniciada em 1999 com o nome de Ateliê de Gestão e Competências. Compreendia uma carga horária entre 12 e 20 horas de trabalho posicionadas nas últimas semanas do programa. Por meio de dinâmicas e da aplicação de questionários, procurava-se identificar e sistematizar quais conteúdos e experiências aprendidas no curso o grupo considerava mais relevantes. Entre o último trimestre de 1999 e outubro de 2006, foram avaliadas cerca de 600 alunos em 32 turmas - nove mestrados profissionais, seis MBAs e 17 especializações em gestão lato sensu, sediadas em quatro diferentes instituições de ensino brasileiras.

Durante esses sete anos de aplicação, tanto os procedimentos quanto sua formatação foram sofrendo as mudanças que entendemos necessária em função da avaliação pelos alunos e da apropriação de teorias e experiências. No começo, a atividade compreendia uma única intervenção e avaliação ao final do curso. Ela iniciava pelo compartilhamento da noção de competência - um dos eixos conceituais do método - e, com essa base, era realizada a avaliação da aprendizagem e do desenvolvimento de competências durante o curso, segundo a percepção dos alunos. 
Mais tarde, entendemos ser importante associar a avaliação dos resultados de aprendizagem realizada ao final do curso com levantamento de expectativas de aprendizagem no início deste. Isso nos levou a uma nova formatação baseada em duas intervenções, uma no início e outra no final dos programas. Em alguns desses programas, tivemos ainda a oportunidade de conhecer um pouco do percurso da aprendizagem dos alunos durante o curso e, então, incluímos uma terceira intervenção, mais curta, de quatro horas, restrita a situações específicas.

Apresentamos adiante alguns dos principais resultados da avaliação da aprendizagem de conteúdos e experiências durante os PPFGs. Para um análise mais atualizada e consistente, selecionamos apenas os resultados obtidos nos quatro anos finais da pesquisa, totalizando cerca de 300 alunos em quatro turmas de mestrado profissional, três de MBA e sete de especialização lato sensu, como já mencionado.

\section{Sistematização e comparação entre expectativas e resultados de aprendizagem em PPFGs, segundo a percepção dos alunos}

Um dos resultados mais importantes de nossa análise foi a comparação entre as expectativas dos alunos, levantadas no início dos cursos, e a avaliação de aprendizagem realizada no final, cujas percepções principais são sistematizadas no quadro 1 .

Quadro 1 - Sistematização e comparação entre expectativas prévias e resultados de aprendizagem no final do PPFG, segundo a percepção dos alunos

\begin{tabular}{l}
\hline $\begin{array}{l}\text { Expectativas } \\
\text { (levantadas no início dos cursos) }\end{array}$ \\
Saber empregar conceitos, métodos e \\
ferramentas da gestão contemporânea \\
de maneira oportuna e adequada \\
(quando, como e onde) \\
Visão estratégica e de negócios - \\
desenvolver capacidade de analisar, \\
relacionar e interpretar situações, \\
cenários e informações de origens e/ou \\
natureza diferentes em sua atividade \\
profissional \\
\hline Capacidade de atuar em ambientes \\
mais complexos ou diferentes - nos \\
quais intervêm atores pouco conhecidos \\
Identificar oportunidades no negócio, \\
desenvolver novos projetos e \\
apresentar e defender idéias novas \\
\hline Explorar e desenvolver competências \\
relacionais - relacionamento, \\
negociação e \\
Networks
\end{tabular}

Aprender com seus próprios erros e acertos - capacidade de refletir, avaliar e aprender na ação

\section{Resultados De Aprendizagem \\ (levantados no final dos cursos)}

Teve contato e explorou conceitos e práticas associados à gestão contemporânea. Entretanto, concluído o curso, entende que ainda não construiu uma visão pessoal mais sistemática e abrangente acerca da aplicação de todo esse conhecimento e experiência

Analisou, criticou e sistematizou as principais idéias e questões de livros, artigos e documentos em geral. Algumas vezes, associou esses conteúdos à realidade da sua empresa ou com as de colegas, mas sempre no ambiente da sala de aula. Todavia, entendem que seria importante experimentar algumas dessas capacidades no ambiente de trabalho

Foi estimulado, no curso, a se auto-avaliar de forma mais objetiva, em termos de seu desempenho, o que lhe deu mais autoconfiança para atuar em outros ambientes e com outros atores

No decorrer do curso, teve contato com muitas idéias e perspectivas inovadoras. Entretanto, foram mais raras as oportunidades de pôr isso em prática na sua atividade profissional

Durante o curso precisou compartilhar visões e maneiras de pensar, relacionar-se e explorar sua tolerância com pessoas que normalmente pensam e agem de forma diferente. Contudo, não sabe o quanto dessa experiência foi efetivamente internalizada e o quanto ficou restrito ao contexto do curso

Alguns dos conteúdos e experiências do curso estimularam exercícios de reflexão e avaliação acerca de seu próprio desempenho. Em tese, esse processo poderia viabilizar processos de auto-aprendizagem a partir de sua própria experiêrncia no trabalho. Entretanto, entende que carece de uma sistemática para isso. Por outro lado, a sensibilização para esse tema, desenvolveu, entre parte significativa dos alunos, a convicção de que esse aspecto é fundamental para o crescimento pessoal e profissional 
Uma análise da primeira coluna revela que, no início dos cursos, os alunos tinham a expectativa de que os conhecimentos e experiências a serem desenvolvidos nesses programas se caracterizassem por um potencial de maior aplicabilidade e contextualização a suas atividades profissionais, assumindo, então, essa aprendizagem, formas próximas das chamadas competências gerenciais. Em outras palavras, as expectativas dos alunos em relação a esses programas apontavam também para um processo de "concretização de competências", especialmente, aquelas mais valorizadas no atual ambiente de negócios (visão estratégica e de negócios, saber atuar em ambiente mais complexos, orientação para resultados, saber empregar conceitos e métodos de gestão contemporânea, estabelecer redes de relacionamento). ${ }^{2}$

Entretanto, na avaliação dos próprios alunos, sua aprendizagem esteve mais próxima do desenvolvimento de capacidades e potenciais do que da efetivação de competências. É certo que a maioria deles entende que as capacidades desenvolvidas nos cursos constituem recursos indispensáveis para efetivar competências. Contudo, defendem que teria sido importante experimentar a aplicação de métodos e conceitos em seus ambientes de trabalho. Aliás, essa percepção dos alunos associa-se a abordagens muito difundidas nos últimos anos algumas delas já destacadas em tópico anterior -, as quais, embora, partindo de experiências e princípios diferentes, acabam levando à conclusão de que a questão da aprendizagem no campo gerencial é extremamente dependente da interação social. Em outras palavras, a consolidação da aprendizagem não dispensaria a relação com as práticas de trabalho, nem com o contexto social das organizações. (BROWN ; DUGUID, 1996; BURGOYNE; REYNOLDS, 1997; NICOLINI; GHERARDI; YANOW, 2003; RAELIN, 1997; REVANS, 1986; WENGER, 2003).

Por outro lado, esses mesmos alunos não negam que as "capacidades intelectuais" - segundo eles, as mais exploradas nos cursos - estão entre as maiores carências da atividade gerencial cotidiana, expressa por "muita ação e pouca reflexão". Nesse contexto, valorizar capacidades intelectuais como organização de textos, análise e crítica, síntese, associação de idéias e outras semelhantes parece fazer muito sentido.

Em seu Ciclo de Aprendizagem Vivencial, D. Kolb destaca a reflexão como um dos 4 processos-chave através dos quais um indivíduo conscientiza-se do sentido de suas experiências, e nesse processo constrói as bases para futuras ações e iniciativas de apropriação de idéias novas ou adaptadas ao processo. (PELTIER; HAY; DRAGO, p.252)

\section{Destaques - o que de mais importante se aprendeu no curso, segundo a percepção dos alunos:}

- a despeito das muitas percepções levantadas entre os participantes desses programas, foi dado destaque quase unânime à exploração, no curso, da capacidade de análise e associação de cada um, o que muitos resumiram mais ou menos da seguinte forma: "o que melhor se aprendeu no curso foi a capacidade de ver e analisar o mundo";

É paradoxal observar que essa perspectiva da aprendizagem, predominantemente no campo cognitivo, não faz necessariamente parte do quadro de expectativas levantadas pelos alunos no início do curso, mesmo porque esse tipo de aprendizagem não lhes parece, à primeira vista, aplicável em suas atividades profissionais. Entretanto, como observado anteriormente, parece não terem dúvidas de sua importância. Nesse sentido, uma expressão muito repetida em vários cursos, quando da avaliação final, foi: "Nunca mais li um jornal da mesma maneira, depois do curso", o que representa adequadamente a mudança de postura e visão do mundo.

- outro aspecto que apresentou alta frequiência na percepção de aprendizagem dos alunos, foi o que consideraram como um salto qualitativo em seus conhecimentos e habilidades gerenciais, através do compartilhamento de conceitos, métodos e ferramentas de gestão. Segundo expressão dos próprios alunos,

\footnotetext{
${ }^{2}$ Segundo a noção de competência aqui empregada e já explicitada anteriormente (Dutra, 2004; Ruas, 2005.), os conhecimentos e habilidades compartilhados durante o curso tomam a forma de competência, se colocados em ação numa determinada situação real de trabalho, de preferência, na própria atividade profissional.
} 
trata-se da capacidade "de entender diferentes perspectivas do que acontece na administração contemporânea";

- a aprendizagem via interação com os colegas de curso foi destacada como uma forma de compreender outras e diferentes perspectivas da gestão contemporânea. "Dentre outros aspectos, aprendi a relacionar melhor minha área de atuação com outras áreas da empresa". Nesse eixo de aprendizagem, destaque para trabalhar em equipe, para a tolerância com o diferente, a negociação (em geral, também destacam aspectos teóricos desse tema), visão sistêmica, improvisação, relações interpessoais, adaptabilidade e saber ouvir. Todas essas competências podem ser classificadas como interativas, o que novamente destaca a importância do aprendizado social e prático;

- ao final do curso, muitos alunos desses programas (PPFGs) entendem que os processos de aprendizagem, a visão mais abrangente, o diploma e a relação com colegas atuando em outros negócios, além de outros elementos que fazem parte das suas trajetórias nos cursos, fortaleceram sua autoconfiança para atuar em novas situações ou outros ambientes;

- concluindo, apesar de reafirmarem a importância da atualização em conceitos e métodos da gestão contemporânea e de desenvolverem no decorrer do curso uma visão geral sobre as diferentes áreas de gestão e da análise de cenários e negócios, grande parte dos alunos entende que o maior impacto dos PPFGs está associado ao desenvolvimento de sua capacidade intelectual. São raros os que não reconhecem a importância desses cursos para seu crescimento pessoal e profissional.

\section{Observações sobre os resultados sistematizados, destacando o impacto dos PPFGs nas competências e no desempenho dos alunos-gestores}

- nossa análise revelou que o aspecto mais valorizado, na percepção da maioria dos alunos dos programas avaliados, foi o fortalecimento de sua capacidade intelectual e analítica. Embora não se possa relacionar de forma direta o impacto dessa capacidade no desempenho dos profissionais de gestão, não há dúvida de que ela contribui significativamente em termos de ampliação e renovação da forma de pensar e atuar, o que é muito significativo no desenvolvimento de uma carreira gerencial ;

- da mesma forma, a exploração da autoconfiança, da capacidade de perceber a si próprio em suas atividade no contexto organizacional e a tolerância, além de outras habilidades exploradas durante o curso, expressam o desenvolvimento de competências, mesmo que de formas não deliberadas. Trata-se de habilidades exploradas durante a realização de atividades do curso, as quais, se colocadas em situação de trabalho, assumem a condição de competências. Entretanto, a avaliação dos desdobramentos desse tipo de capacidades no desempenho dos egressos desses cursos não é tarefa fácil;

- por outro lado, a maior parte dos conteúdos e experiências explorados no decorrer dos cursos não apresentam condições de adaptação para serem aplicadas diretamente em situações profissionais Por isso, salvo situações muito específicas, a mobilização dessas capacidades no contexto de trabalho e já na condição de competências, torna-se um processo praticamente dependente da iniciativa do aluno;

- no entanto, a prática cotidiana e profissional dos alunos, as dificuldades para dar conta simultaneamente das demandas do curso e do trabalho, o pouco tempo de que dispõem para atuarem/refletirem sobre essa articulação entre a "teoria da aula" e a "prática das atividades profissionais", tudo isso acaba por estabelecer, para o aluno, uma certa concorrência entre esses mundos. Nessas condições, é muito improvável que ele disponha de tempo, vontade e método para realizar essa articulação de maneira isolada;

- os resultados também apontam para a contradição entre as expectativas dos alunos em relação ao desenvolvimento de competências e as suas percepções no final dos cursos, dentre as quais destacam as dificuldades de associarem os conteúdos explorados nas aulas com suas atividades profissionais. À primeira vista, pode-se concluir que, por desconhecimento, os alunos não saibam exatamente o que procuram ou, que os PPFGs menosprezem a questão do desenvolvimento de competências. Embora possa haver um tanto de verdade nessas duas afirmações, em nosso entendimento esse aparente paradoxo se deve, sobretudo, à falta 
de métodos pedagógicos que viabilizem a articulação entre conteúdos do curso e desenvolvimento de competências;

- embora recentemente mais sensíveis à problemática das competências, são raros os procedimentos pedagógicos que no decorrer dos cursos, dão condições aos alunos de colocarem em ação conhecimentos e experiências em seu ambiente de trabalho, de forma mais sistemática. Estamos considerando "procedimentos sistemáticos" as situações projetadas, nas quais a experiência de aplicar no contexto de trabalho determinada capacidade ou conhecimento desenvolvido em PPFGs possa ser monitorada, avaliada e repensada durante e após esse processo;

Pelo que foi observado anteriormente, quais aspectos podem contribuir para o debate sobre a efetividade do aprendizado em PPFGs em relação ao desenvolvimento de competências e à melhoria do desempenho dos egressos desses programas? Não há dúvida de que os resultados apontados reforçam a necessidade de se repensar conceitos, sistemáticas e procedimentos que sejam capazes de articular os nexos entre a aprendizagem em sala de aula e o desenvolvimento de competências no ambiente de trabalho. Esses mesmos resultados também revelaram elementos através dos quais se pode construir os referidos nexos.

O próximo e conclusivo tópico seleciona e caracteriza princípios, conceitos, abordagens e procedimentos como referências para a construção das conexões entre a "teoria da aula" e a "prática das atividades profissionais", sem descuidar, no processo, das aprendizagens no campo cognitivo.

\section{Princípios, conceitos, abordagens e procedimentos de aprendizagem capazes de articular teoria e prática em programas de pós- graduação dedicados à formação gerencial}

O objetivo deste tópico é selecionar e caracterizar princípios, conceitos e procedimentos capazes de, em ambiente de PPFGs, criar condições para a articulação sistemática da relação entre aprendizagem em sala de aula e o desenvolvimento de competências no ambiente de trabalho.

\section{Princípios e conceitos como referência para aprendizagem: articulando sala de aula e ambiente de trabalho}

- a noção de competência está associada à mobilização de capacidades num contexto e à efetivação de uma entrega;

- uma condição indispensável para a aprendizagem é a disponibilidade e o interesse dos alunos: de fato, o sujeito da aprendizagem é sempre o aluno, embora em muitos casos o foco do processo seja, equivocadamente, colocado na performance do professor/facilitador. Contudo, se é o aluno o protagonista efetivo desse processo, sua disponibilidade é crucial. Sem essa condição, o curso pode prosseguir, mas as condições de aprendizagem serão muito menores.

Diferentes teorias têm mostrado que quanto mais significados o conteúdo em aprendizagem apresentar para o aluno, mais facilitado será esse processo. Daí a estratégia pedagógica de articular o conteúdo da aprendizagem com as experiências do aluno, o que nos coloca próximo do conceito de aprendizagem significativa. (MOREIRA, 1999). No caso específico da administração, esse princípio sustenta que a aprendizagem de um novo conceito ou método será mais viável e mais rápida se for adequadamente associada a um problema profissional, a uma atividade atual ou à experiência anterior do aluno.

- a aprendizagem em administração e a relação entre teoria e prática: não é por acaso que a área de administração é classificada como uma das ciências sociais aplicadas. De fato, grande parte dos conceitos e métodos gerados no campo da administração começam pela necessidade de solução de problema reais. Já seus modelos e procedimentos resultam de avaliação, da sistematização e da validação de experiências bemsucedidas. Por isso, mesmo os melhores caminhos da aprendizagem em administração passam por uma articulação consistente entre teoria e prática; ou seja, por uma experiência de aplicação sistemática, em contexto de trabalho real, dos conceitos e métodos desenvolvidos nos processos de formação. 
Inspirado em Piaget, "toda a aprendizagem é produto de ação", Dehler (2006, p.639) entende que essa afirmação tem importantes implicações pedagógicas e que as pessoas aprendem efetivamente quando atuam em problemas reais, instalados em seus próprios contextos (experiências). Por isso mesmo, esse autor conclui que um desafio permanente para os educadores no campo da administração é o desenvolvimento de pedagogias que consigam uma articulacão adequada e sempre difícil entre o processo de simplificação inerente à aplicação de métodos e ferramentas de gestão e a complexidade das relações no ambiente organizacional. (BURGOYNE; REYNOLDS, 1997; RAELIN, 1997; REVANS, 1986).

- uma forte convergência entre a aprendizagem em administração e a noção de competência, em torno da expressão "mobilização no contexto": de um lado, a noção de competência caracteriza-se pela mobilização de capacidades num contexto específico; de outro, a aprendizagem em administração parece consolidar-se quando da experiência com os conteúdos. Por isso, tanto a consolidação da aprendizagem em administração quanto a legitimação de competências apresentam uma condição comum - a necessidade de mobilização no ambiente de trabalho. Por isso mesmo, os processos de aprendizagem em PPFGs não podem prescindir da mobilização de determinados conhecimentos e habilidades (capacidades), desenvolvidos em sala de aula. (Ruas, 2001).

\section{Abordagens e procedimentos como referência para aprendizagem articulando sala de aula e ambiente de trabalho}

a) Processos de compartilhamento progressivo, entre os grupos de alunos, de princípios e conceitos acerca da aprendizagem

O desafio de mobilizar e orientar os alunos de um programa de formação gerencial para o desenvolvimento de competências - com base na articulação entre teoria e prática - demanda que eles compartilhem um quadro conceitual sobre os processos de aprendizagem e um razoável portfólio de experiências associadas a essa aprendizagem. Além de mobilizá-los, tal compartilhamento tem a função de esclarecer-lhes os princípios desses processos de aprendizagem, podendo ocorrer em eventos formalmente organizados e periódicos - como, por exemplo, oficinas de quatro a oito horas, no final de módulos -, os quais compreendem um conjunto de disciplinas. É conveniente, porém que esse desenvolvimento não fique limitado a ações isoladas. Na verdade, estamos tratando de uma forma de aprendizagem que exigirá mudanças na maneira de pensar e agir dos alunos (e também dos professores que atuam nesse tipo de atividade). Por isso, a expressão aprendizagem como processo é referência nessa etapa. A internalização da relação entre teoria e prática não pode ser entendida como uma atividade eventual, mas, sim, como uma dinâmica.

b) Abordagens articulando a relação entre conceitos/idéias e experiências - o ciclo de aprendizagem vivencial. Desenvolvido por Kolb (1997), esse ciclo compreende quatro processos principais, articulados entre si:

Processo 1 - interação com novas idéias, conceitos ou métodos: etapa que expressa a apropriação de novas idéias, conceitos ou métodos, como, por exemplo, durante uma au la;

Processo 2 - adequação ou projeto de aplicação de novas idéias, conceitos ou métodos em situação real: a fim de resolver um problema ou realizar um processo de mudança e melhoria;

Processo 3 - experiência concreta de aplicação do projeto numa situação real;

Processo 4 - observações, avaliações e reflexões sobre a aplicação e seus resultados.

Esse ciclo apresenta diferentes perspectivas. Antes de tudo, significa um processo de consolidação da aprendizagem, já que para Kolb, a aprendizagem deve ser entendida como uma trajetória cíclica. Se começar por um processo experiencial, a aprendizagem vai ser consolidada a partir da reflexão. Se o ponto de partida for a apreensão de novos conceitos e métodos, a consolidação da aprendizagem ocorrerá a partir da experiência concreta de aplicação desses conhecimentos. Portanto o que é forte no ciclo de aprendizagem vivencial é a relação reflexão/observação, de um lado, e o projeto e a experiência, de outro. Nesse sentido, pensar e agir é uma das maiores dificuldades da atividade gerencial. 
Embora possa ser empregado em várias circunstâncias, o ciclo de aprendizagem vivencial tem sido especialmente importante em programas de formação gerencial, como "elemento de que sistematiza" a relação entre teoria e prática. Poder-se-ia também considerar a chamada "teoria da ação", mais especificamente as configurações "single loop" e "double loop", como uma referência de aprendizagem cíclica neste trabalho . (ARGYRIS; SCHON, 1996)

c) Abordagens que facilitem o trânsito de informações, conhecimentos e experiências entre as pessoas e grupos: as comunidades do conhecimento. $\mathrm{O}$ tratamento da questão da educação e formação interpessoal tem incorporado as chamadas formas sociais de aprendizagem. (BROWN; DUGUID, 1996; LAVE; WENGER, 2001; NICOLINI; GHERARDI.; YANOW, 2003). Dentre os fundamentos dessa abordagem está o pressuposto de que a interação em ambiente coletivo pode exercer um importante efeito mediador sobre os processos cognitivos e conceituais dos indivíduos que dele participam, princípio atribuído à Wygotsky (REGO,1999). A reflexão dos indivíduos é influenciada pelo grupo no qual atuam. A combinação dos processos intelectuais e sociais constitui uma característica fundamental dos conhecimentos adquiridos através do grupo. Por isso, as condições de aprendizagem em PPFGs são muito semelhantes às condições que referenciam a abordagem associada às formas sociais de aprendizagem. Nesse processo, muitos conceitos e princípios são construídos a partir da tensão entre a compreensão conceitual do grupo e a dos indivíduos que o compõem. De Laat e Simons (2002, p.15) apresentam um exemplo dessa dinâmica:

A compreensão pode divergir entre os indivíduos e também entre os indivíduos e o grupo. Essa tensão é a força motriz dos processos coletivos do grupo. Assim, quando um membro do grupo exprime uma opinião relacionada com o entendimento comum do grupo, essa opinião constitui uma tentativa de síntese entre o seu entendimento pessoal e o do grupo. Os outros membros do grupo comparam essa nova síntese com o seu entendimento pessoal da versão aceita pelo grupo e o seu desacordo pessoal relativamente a essa versão.

Como resultado dessa dinâmica, o grupo acaba construindo novos significados e novos entendimentos conceituais e experienciais, processo no qual a interação entre a cognição comum e a individual constituem os elementos fundamentais da construção coletiva.

Como se observa, não há dúvida de que nos processos de formação em PPFGs são muitas as oportunidades em que os alunos estabelecem uma relação entre novos e prévios conhecimentos. Desse processo, resulta a construção (muitas vezes, coletiva) de novas representações dos conceitos, princípios e métodos apresentados e compartilhados no curso. A aprendizagem é um processo pelo qual o aluno personaliza novas informações, conferindo-lhe um significado a partir de experiências anteriores. (MOREIRA, 1999). Por isso, o estímulo à interação, tanto formal quanto informal, entre os alunos num curso dessa natureza - interação que confronte experiências pessoais e profissionais com os novos conceitos e idéias - pode constituir um instrumento muito poderoso de articulação entre a teoria da sala de aula e as práticas do ambiente de trabalho. Nesse sentido, em nossa avaliação da percepção de aprendizagem entre alunos de PPFGs, observamos que um dos principais destaques é exatamente o aprendizado com os colegas de aula. Por que, então, não fazer dessa experiência, geralmente informal e eventual, um procedimento sistemático de aprendizagem?

d) Procedimentos que contribuam para fazer da articulação entre sala de aula e o ambiente de trabalho um processo concreto e sistemático: o diário de bordo. Trata-se de um instrumento empregado com a finalidade de registrar e sistematizar as experiências concretas e individuais de articulação entre os conhecimentos da sala de aula e a experiência do ambiente de trabalho. Esse procedimento deve estimular, no contexto da atividade profissional, os processos de experimentação dos conteúdos e conceitos desenvolvidos no curso. Em outras palavras, é um instrumento para registrar e acompanhar a mobilização de capacidades no ambiente de trabalho. A partir dele, os alunos são periodicamente estimulados a compartilhar os registros de seus diários de bordo e apresentar as principais experiências de desenvolvimento de competências vivenciadas recentemente. Se utilizado com regularidade, o diário de bordo pode tornar-se um importante procedimento para concretizar e sistematizar a relação entre sala de aula e o ambiente de trabalho. Além disso, ao final do curso, o diário de 
bordo será um documento consistente acerca do desenvolvimento de competências e habilidades durante o curso.

- objetivo do diário de bordo - instrumentalizar a articulação entre conteúdos da sala de aula e o ambiente de trabalho, visando desenvolver competências;

- como: articulação entre teoria e prática; ou seja, observar e registrar a aplicação, em contexto profissional, de conceitos e métodos desenvolvidos no curso;

- exemplos de registros e observações a serem desenvolvidos:

- $\quad$ observação direta - registrar situações nas quais uma competência foi colocada em ação, com base na experiência pessoal ou de terceiros;

- observação indireta - registrar situações em que a ausência de uma competência gerou um resultado indesejado;

- observação analítica - identificar quais capacidades (conhecimentos, habilidades e atitudes) compõem uma competência mobilizada pessoalmente ou por terceiros, no local de trabalho;

- observação reflexiva - relacionar quais conteúdos e experiências desenvolvidas em sala de aula podem contribuir para o desenvolvimento das capacidades associadas a uma competência almejada.

Conforme se constata pelo exemplo anterior, as observações podem apresentar níveis progressivamente superiores de complexidade.

\section{Considerações finais}

Neste artigo tratamos de uma questão recorrente acerca dos programas de pós-graduação em formação gerencial (PPFGs): os diferentes tipos de impactos que exercem no desenvolvimento de competências gerenciais e no desempenho de seus alunos. Essa questão resulta da análise da percepção de aprendizagem de aproximadamente 300 alunos de diferentes turmas, cursos e instituições.

Dentre os vários aspectos levantados a partir de pesquisas realizadas junto a esses alunos - alguns positivos e até surpreendentes -, uma das considerações mais freqüentes foi a demanda por maior aproximação entre os conteúdos e atividades de aula e a experiência profissional dos participantes, a fim de que o curso possibilite a mobilização e o desenvolvimento de competências de uma maneira mais sistemática. A partir dessa perspectiva, entendemos que seria importante buscar formas de articular mais intensa e sistematicamente a relação entre o que se denominou neste artigo de "teoria da aula" e as "práticas de trabalho no ambiente organizacional", como uma alternativa para o desenvolvimento de competências, no contexto de PPFGs. Esse aspecto tem sido bastante explorado na recente literatura internacional sobre aprendizagem, com destaque para as chamadas formas sociais de aprendizagem, cujos processos centrais aparecem como interações entre, de um lado, teoria e prática e, de outro, indivíduos e ambiente/coletivos. Assim, baseados nas experiências de monitoramento da aprendizagem em PPFGs e nas abordagens teóricas aqui exploradas, concluímos este artigo construindo referências capazes de contribuir para processos de articulação entre a teoria da aula e as práticas de trabalho no ambiente organizacional.

Dentre os princípios selecionados, uma forte influência de teorias da educação e da aprendizagem; entre os procedimentos destacados, buscou-se fundamentos em abordagens de aprendizagem nas organizações e na gestão do conhecimento, tais como ciclos de interação entre pensamento e ação, aprendizagem no espaço de trabalho e sistemas sociais de aprendizagem. Entendemos que esses princípios e procedimentos podem acrescentar novos elementos ao debate sobre a contribuição de programas de pós-graduação em formação gerencial para o desenvolvimento de competências na atividade profissional de seus alunos. 


\section{Referências}

AGUT, S.; GRAU, R. Improving management performance in rapidly changing organization. Human Resource Development Quarterly, v.13, n.1, p.31-51, Sept. 2002.

ANDRADE, J. C. S.; MAHEU, C.D \& OLIVEIRA, F.R.S. Um olhar sobre a práxis pedagógica do mestrado profissional em administração da Universidade Federal da Bahia. In: ENANPAD 28., Curitiba, 2004.

ANTONELLO, C. S; DUTRA, M.L.S. Projeto Pedagógico: Uma Proposta para o Desenvolvimento de Competências de Alunos do Curso de Administração, com foco no Empreendedorismo. In ENANPAD, 29, Brasília, 2005.

ARGYRIS, C; SCHON, D. Organizational learning II. Theory, method and practice. N. York: Addison-Wesley, 1996. -

BROWN, J.S.; DUGUID, P. Organizational learning and communities of practice- toward a unified view of working, learning and innovation. In: COHEN, M. D.; SPROULL, L. S. Organizational learning. Organization science. [S.I.]: Sage, 1996.

BURGOYNE J; REYNOLDS, M. (Ed.). Management learning: integrating perspectives in theory and practice. London: Sage, 1997.

CONGER, J.; XIN, K. Executive education in the 21st Century. J ournal of Management Education, v.24, n.1, p.73-101, 2000.

DAVEL, E.; VERGARA, S. Revitalizando a Relação Ensino-Aprendizagem em Administração por meio de Recursos Estéticos. In Enanpad, 28, Curitiba, 2004

DEHLER, G. E. Using action research to connect practice to learning: a course project for working management studies. Journal of Management Education, v.30, n.5, p.636-669, Oct. 2006.

DE LAAT, M.; SIM ONS, R. J. Aprendizagem coletiva: perspectivas teóricas e apoio à formação de redes. Revista Europeia - Formação Profissional, Lisboa, n.27, 2002.

DUTRA, J. Competências - conceitos e instrumentos para a gestão de pessoas na empresa moderna. São Paulo: Atlas, 2004.

FESTINALI, R.C. A Formação de Mestres em Administração: Por onde Caminhamos? In ENANPAD, 29, Brasília, 2005

FISCHER, T. M. D. A difusão do conhecimento sobre organizações e gestão no Brasil: seis propostas de ensino para o decênio $2000-2010$. RAC Edição Especial, 2001.

FISCHER, T.M.; DAVEL, E.; VERGARA, S.C.; GHADIRI, S.C. Razão e Sensibilidade no Ensino em Administração: a Literatura como Recurso Estético. In ENANPAD, 30, Salvador, 2006.

GHERARDI, S.; NICOLINI, D. To transfer is to transform: the circulation of safety knowledge. In NICOLINI, D; GHERARDI, S.; YANOW, D. Knowing in organizations. NY: Sharpe, 2003.

ISABELLA, L. Using existing teams to teach about teams: how an MBA Course in managing teams helps students and the program. Journal of Management Education, v.29, n.3, p.427-452, June 2005.

KOLB, D. A gestão e o processo de aprendizagem. In: STARKEY, K. Como as organizações aprendem. São Paulo: Ed. Futura/Zumble, 1997.

LATHAM, G; LATHAM, S; WHYTE, G. Journal of Management Education, v.28, n.1, p.3-18, Feb. 2004.

LAVE J.; WENGER E. Situated learning: legitimate peripheral participation. Cambrigde, UK: Cambridge University Press, 2001.

MAZEN, A.; JONES, M.; SERGENIAN, G. Transforming the class into a learning organization. Management Learning, v.31, n.2, p.147-161, 2000.

MINTZBERG, H.. MBA? Não, obrigado! Porto Alegre: Bookman, 2006.

; GOSLING, J. Educando administradores além das fronteiras. RAE, v.43, n.2, p.29-43, 2003.

M OREIRA, M. A. Teorias da aprendizagem. São Paulo: EPU, 1999.

NASSIF, V.M.j; GHOBRIL,A.N.;BIDO, D.S. É Possível Integrar a Teoria à Prática no Contexto de Sala de Aula? Um Resposta através da Pesquisa-Ação em Curso de Administração. In ENANPAD, 29, Brasília, 2005.

NICOLINI, D; GHERARDI, S.; YANOW, D. Introduction: toward a practice-based view of knowing and learning in organizations. In: NICOLINI, D; GHERARDI, S.; YANOW, D. Knowing in organizations. NY: Sharpe, 2003

NUNES, S.C.; FERRAZ, D.M. A Reforma do Ensino no Brasil e a Inserção da Noção de Competências: Um Estudo Empírico em Instituições de Educação Superior. In ENANPAD, Brasília, 2005. 
PELTIER, J.W; HAY, A.;DRAGO,W. The reflective learning continuum: reflecting on reflection. Journal of Marketing Education, v.27, n.3, p.250-263, 2005.

PFEFFER, J.; FONG, C. T. O fim das escolas de negócios. RAE, v.43, n.2, p.11-28, 2003.

RAELIN, J. A model of work based-learning. Organization Science, v.8, Nov./Dec. 1997.

; COGHLAN, D. Developing managers as learners and researchers: using action learning and action research. Journal of Management Education, v.30, n.5, p.670-689, Oct. 2006

REGO T. C. Vygotsky. Petrópolis: Vozes, 1999 (7a.ed).

REVANS, R. Action learning and the cowboys. Organization Development Journal, n.4, p.71-80, 1986.

RUAS, R. Desenvolvimento de competências gerenciais e a contribuição da aprendizagem organizacional. In: FLEURY, M. T;; OLIVEIRA JUNIOR, M. (Org.). Gestão estratégica do conhecimento. São Paulo: Atlas, 2001.

Mestrado modalidade profissional: em busca da identidade. RAE, v.43, n 2., p.55-63, 2003.

Gestão por competências: uma contribuição à estratégia das organizações. In: RUAS, R.; ANTONELLO, C. S.; BOFF, L. H. Aprendizagem organizacional e competências. Porto Alegre: Bookman, 2005.

RUAS, R ; WOOD J R, T. M obilizando Competências Gerenciais com apoio de Recursos Dramáticos: uma Dinâmica orientada para Ensino em Administração In ENEO, 4, Porto 2006. SOUZA, E. C. L.; SOUZA, C.C.L.;ASSIS, S.A.G.; ZERBINI, T. M étodos e técnicas de ensino e recursos didáticos para o ensino do empreendedorismo em IES brasileiras. In: ENANPAD, 28., Curitiba, 2004.

STAHL, L. As expectativas dos alunos em relação ao desempenho de seus professores: um estudo numa IES Pública. In ENANPAD, 28, Curitiba, 2004

VOCÊ S/A. São Paulo, p.32, 3 nov. 2006.

WENGER,E. Communities of Practice and Social Learning Systems.In NICOLINI, D.; GHERARDI, S. \& YANOW,D. Knowing Organizations. A Practice-Based Approach. N.Y, Sharpe Ed , 2003.

WOOD JUNIOR, T.; PAULA, A. P. P. O fenômeno dos MBAs brasileiros: hibridismo, diversidade e tensões. RAE, v.44, n.1, p.116- 129, 2004.

ZARIFIAN, P. Objetivo competência. São Paulo: Atlas, 2001. 